\title{
Metabolic diagnosis and medical prevention of calcium nephrolithiasis and its systemic manifestations: a consensus statement
}

\author{
Giovanni Gambaro ${ }^{1} \cdot$ Emanuele Croppi $^{2} \cdot$ Fredric Coe $^{3} \cdot$ James Lingeman $^{4}$.

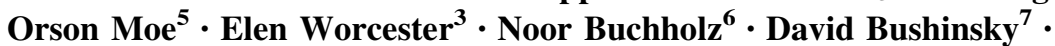 \\ Gary C. Curhan ${ }^{8}$ - Pietro Manuel Ferraro ${ }^{1} \cdot$ Daniel Fuster $^{9} \cdot$ David S. Goldfarb $^{10}$ \\ Ita Pfeferman Heilberg ${ }^{11}$ - Bernard Hess ${ }^{12} \cdot$ John Lieske $^{13}$ - Martino Marangella ${ }^{14}$. \\ Dawn Milliner ${ }^{15}$ - Glen M. Preminger ${ }^{16}$ - Jose' Manuel Reis Santos ${ }^{17}$. \\ Khashayar Sakhaee $^{18}$ - Kemal Sarica ${ }^{19}$ - Roswitha Siener ${ }^{20}$ - Pasquale Strazzullo ${ }^{21}$. \\ James C. Williams ${ }^{22}$ - The Consensus Conference Group ${ }^{1}$
}

Received: 10 May 2016/Accepted: 20 June 2016/Published online: 25 July 2016

(C) The Author(s) 2016. This article is published with open access at Springerlink.com

\begin{abstract}
Background Recently published guidelines on the medical management of renal stone disease did not address relevant topics in the field of idiopathic calcium nephrolithiasis, which are important also for clinical research.
\end{abstract}

Members of the "The Consensus Conference Group" are listed in Acknowledgments.

Emanuele Croppi

emcroppi@mark.it

Giovanni Gambaro

giovanni.gambaro@unicatt.it

1 Department of Nephrology and Dialysis, A. Gemelli University Hospital, Catholic University of the Sacred Heart, Rome, Italy

2 A.S.L. 10, Florence, Italy

3 Department of Nephrology, University of Chicago Medicine, Chicago, USA

4 Department of Urology, Indiana University School of Medicine, Indianapolis, USA

5 Department of Internal Medicine, Southwestern Medical Center, University of Texas, Dallas, USA

6 Department of Urological Surgery, Sobeh's Vascular and Medical Center, Dubai, UAE

7 Department of Nephrology, Medical Center, University of Rochester, Rochester, USA

8 Renal Division, Brigham and Women's Hospital, Boston, USA
Design A steering committee identified 27 questions, which were proposed to a faculty of 44 experts in nephrolithiasis and allied fields. A systematic review of the literature was conducted and 5216 potentially relevant articles were selected; from these, 407 articles were deemed to provide useful scientific information. The Faculty, divided into working groups, analysed the relevant literature. Preliminary statements developed by each group were exhaustively discussed in plenary sessions and approved.

9 Department of Nephrology, University of Bern, Bern, Switzerland

10 Department of Nephrology, New York Harbor VA Health Care System, New York, USA

11 Department of Nephrology, Sao Paulo University, Sao Paulo, Brazil

12 Department of Internal Medicine and Nephrology, Klinik Im Park Hospital, Zurich, Switzerland

13 Department of Laboratory Medicine and Pathology, Mayo Clinic, Rochester, USA

14 Department of Nephrology, A.S.O Ordine Mauriziano Hospital, Turin, Italy

15 Department of Nephrology, Mayo Clinic, Rochester, USA

16 Department of Urology, Duke University Medical Center, Durham, USA

17 Department of Urology, Catholic University of Portugal, Lisbon, Portugal

18 Southwestern Medical Center, Mineral Metabolism Research, University of Texas, Dallas, USA 
Results Statements were developed to inform clinicians on the identification of secondary forms of calcium nephrolithiasis and systemic complications; on the definition of idiopathic calcium nephrolithiasis; on the use of urinary tests of crystallization and of surgical observations during stone treatment in the management of these patients; on the identification of patients warranting preventive measures; on the role of fluid and nutritional measures and of drugs to prevent recurrent episodes of stones; and finally, on the cooperation between the urologist and nephrologist in the renal stone patients.

Conclusions This document has addressed idiopathic calcium nephrolithiasis from the perspective of a disease that can associate with systemic disorders, emphasizing the interplay needed between urologists and nephrologists. It is complementary to the American Urological Association and European Association of Urology guidelines. Future areas for research are identified.

Keywords Nephrolithiasis - CKD - Bone disease - Diet . Beverages $\cdot$ Renal tubular acidosis

\section{Introduction}

The present document is the result of a Consensus Conference held in Rome on March 26-28, 2015 that concluded the work of an International Faculty of experts in the field of renal stones. The faculty was multidisciplinary, representing nephrology, urology, nutrition, internal medicine, endocrinology, and laboratory medicine, which was desirable in view of the multifaceted nature of nephrolithiasis and in line with the scientific 'tradition' in this field.

In 2014 and 2015, three clinical practice guidelines addressing the medical management of nephrolithiasis were published: the American Urological Association (AUA) [1], American College of Physicians (ACP) [2], and European Association of Urology (EAU) [3] guidelines. These guidelines underlie the interest in this condition that is increasing in prevalence, and is difficult to treat because of its unpredictability, complexity and heterogeneity. Last

19 Department of Urology, Dr. Lutfi KIRDAR Kartal Research and Training Hospital, Istanbul, Turkey

20 Department of Urology, University of Bonn, Bonn, Germany

21 Department of Internal Medicine, University of Naples, Naples, Italy

22 Department of Anatomy and Cell Biology, Indiana University School of Medicine, Indiana, USA but not least, they also highlight the need for increased knowledge regarding key pathogenic aspects and newer treatment strategies.

Why another consensus statement on nephrolithiasis? The answer is relatively easy, expressed as three goals:

1. To address questions that have not been addressed by previous documents;

2. To address those questions with a more general perspective for a disease that can be associated with systemic disorders.

3. To emphasize primarily the interplay between urologists and nephrologists, but also with other medical experts in the management of this disorder.

Of course, it is not all black and white, in the sense that some of the questions, or some of the relevant systemic disorders, were in part also addressed by other documents. However, in general, this statement is complementary to the other recent documents; in the areas of overlap, it partially endorses the AUA and EAU guidelines with a few modifications. This consensus statement was born in a strong mixed uro-nephrological collaboration with an accent on some typical renal medicine issues, i.e. chronic kidney disease (CKD), metabolic bone disease (MBD), and with an attempt to define the areas of cooperation.

Furthermore, different from other documents, some of the questions discussed in this statement represent the cutting edge of a relevant new understanding of the disorder (i.e. question \#14: Use of surgical observations for diagnosis); and some are relevant not only from a good clinical practice perspective, but also for future research. For example, this statement addresses how to define the clinical phenotype of the idiopathic calcium nephrolithiasis $(\mathrm{CN})$ patient, and the definition of clinical activity of the $\mathrm{CN}$, both useful in designing randomized clinical trials (RCT), that are largely lacking in this field of medicine.

This document addresses only the so-called idiopathic $\mathrm{CN}$; non-idiopathic calcium stones, uric acid, cystine and struvite stones are addressed just for those aspects needed to identify and manage the idiopathic $\mathrm{CN}$.

\section{Methods}

A Steering Committee which was set up by a previous conference (Nephrolithiasis: a systemic disorder, Rome, March 21-23, 2013) discussed which questions should be asked; these were selected because of clinical relevance, and/or the insufficient consensus on them, and/or not having been addressed by other documents, and/or to address topics for the development of cooperation between nephrologists and urologists. Twenty-seven questions 
were, in the end, proposed to a panel whose members were selected according to their expertise in nephrolithiasis and allied fields.

The task of the Steering Committee was to develop recommendations based on the analysis of the literature or on the consensus of the Faculty for best clinical practice in the management of $\mathrm{CN}$ patients. The whole Faculty, including the Steering Committee, comprised 44 members which were divided into working groups of 4-5 members each to analyse ahead of the conference the relevant literature, and to carry out, whenever necessary, on-line surveys among the community involved in the treatment of renal stone patients, including urologists and nephrologists and other specialists (clinical epidemiologists, nutritionists, biochemists, etc.). Working groups addressed 2-4 questions each. All the work and preliminary statements developed by each group were presented to the Faculty in plenary sessions in Rome where they were exhaustively discussed during 1.5 days, at the end of which each working group met to revise their statements in view of the plenary discussions and the results of other working groups' possibly interrelated results. The following day, the revised versions of all statements were presented to the Faculty, discussed and approved. Following the conference, the consensus statement draft prepared by members of a writing committee was submitted to all members of the Consensus Conference Group for final revision.

\section{Analytical procedure}

The groups performed a systematic review of the literature to retrieve all randomized clinical trials (RCT) that investigated topics relevant to their assigned questions. Cohort and case-control studies in addition to RCTs were also considered in the analysis due to the very small number of RCT-based evidence available in the literature.

Using appropriate search strategies, potentially relevant titles and abstracts published up to June 2014 were retrieved, from which 5216 potentially relevant articles were selected; from these, 3855 records were excluded based on title/abstract; 954 were excluded after screening the abstract or reading the article. In the end, 407 articles were deemed to provide useful scientific information.

The definition of the scientific 'strength' of each statement was based on the AUA categorization (http://www. auanet.org/education/guidelines/management-kidneystones.cfm).

\section{Questions and consensus statements}

\section{Questions \#1 and \#2}

\begin{abstract}
Is the stone patient at risk of CKD?
Is it necessary to implement this information in the evaluation of the renal stone former?

Although the effect size is modest, nephrolithiasis should be viewed as a condition that may lead to CKD. Thus, in patients with renal stones the evaluation of the global risk (comorbidities) of developing $\mathrm{CKD} /$ endstage renal disease (ESRD) is mandatory. Those who are female and overweight, or with frequent urinary tract infections (UTI) or struvite stones, with urinary malformations and urinary diversion, malabsorptive bowel diseases, monogenic disorders and need of repeated stone surgeries have a particularly high risk of CKD/ESRD (Clinical principle).
\end{abstract}

In a registry cohort study, one or more stone episodes were associated with an increased risk of ESRD [adjusted hazard ratio (HR) 2.16, 1.79-2.62], new stage 3b-5 CKD (1.74, 1.61-1.88), and doubling of serum creatinine (1.94, 1.56-2.43). However, the absolute increase in the rate of ESRD associated with stones was small (2.48 per million person days in people with stones versus 0.52 in people without) [4].The risk seems to be greater in women than in men $[4,5]$. In the Olmsted County cohort studies, those stone formers who developed CKD or ESRD were more likely to have a history of hydronephrosis, struvite stones, recurrent UTI, acquired single kidney (15 vs. $3 \%$ ), neurogenic bladder (12 vs. $1 \%$ ), and ileal conduit (9 vs. $0 \%$ ) $[6,7]$. Among the Third National Health and Nutrition Examination Survey (NHANES III) participants, a history of kidney stones in subjects with body mass index (BMI) $\geq 27 \mathrm{~kg} / \mathrm{m}^{2}$ increased the probability of having an estimated glomerular filtration rate (eGFR) $<60 \mathrm{ml} / \mathrm{min} /$ $1.73 \mathrm{~m}^{2}$ compared to overweight non-stone formers [8]. Stone formers with cystinuria, uric acid or struvite stones, renal tubular acidosis, or chronic bowel disorders frequently manifest decreased GFR, and CKD/ESRD [9, 10]. Standard Roux-en-Y gastric bypass and malabsorptive types of bariatric surgery are both associated with an increased risk for stones and CKD [11]. In a multicenter registry study on 5,745 patients undergoing percutaneous nephrolithotomy (PCNL), the risk of CKD was associated with the number of procedures for stone removal [12].

Low quality studies do not permit a confident conclusion on the relevance of kidney damage induced by urological stone procedures and the development and progression of CKD. The 
high-speed of technological advancements in urology does not easily allow for comparison between study cohorts, even when investigated over a short space of time. Although noninvasive and mini-invasive urological procedures for stone removal do damage the kidney to a certain extent, the differentiation of the renal damage due to the urological procedure versus the stone disease itself is a challenge.

\section{Future research directions}

- Studies to evaluate the risk of CKD according to etiology and composition of renal stones.

- Registry studies on the effect of different urological treatments of renal stones. This requires a minimum standard for data acquisition (e.g. stone burden, stone composition, concomitant obstruction, concomitant infection, urological procedure(s), repeated procedures.

- Methods for the evaluation of the renal damage in stone formers.

\section{Questions \#3 and \#4}

\section{Is the calcium stone patient at risk of bone disease} and if so, how should that risk be addressed?

Is it necessary to implement this information in the evaluation of the renal stone former?

Stone patients with hypercalciuria should be evaluated for the global risk of osteoporosis. Those who are at increased risk for osteoporosis should have bone density determined by dual emission X-ray absorptiometry (DXA). (Expert opinion)

Patients should consume an age- and genderappropriate amount of dietary calcium and should be 25-hydroxyvitamin D replete. (Clinical Principle)

Pharmacologic therapy that is directed at reducing recurrent stone formation may also help stabilize bone mineral density. Thiazide diuretics may increase bone density. Alkali decreases bone resorption, especially in patients eating a high animal protein diet, and improves bone mass. (Expert Opinion)

Experts surmise that patients with hypercalciuria often excrete more calcium than they absorb, indicating a net loss of total body calcium. The source of this additional urine calcium is thought to originate from the skeleton. Hypercalciuric stone formers exhibit decreased bone mineral density (BMD) and the decrease is correlated with an increase in urine calcium excretion [13]. The decreased BMD also correlates with an increase in markers of bone turnover, as well as increased rates of fractures [14]. Patients with hypercalciuria, especially those who are at increased risk for osteoporosis, should have bone density determined by DXA. There are few controlled studies in hypercalciuric stone formers with low bone mass $[15,16]$; however, there is a wealth of data in patients with osteoporosis to guide therapy. Patients should consume an age- and genderappropriate amount of dietary calcium and should be 25 -hydroxyvitamin D replete. Pharmacologic therapy that is directed at reducing recurrent stone formation may also help stabilize bone density. Thiazide diuretics lower urinary calcium and may increase bone density [17]. Alkali decreases bone resorption, especially in patients eating a high animal protein diet, and may improve bone mass as well $[18,19]$.

\section{Future research directions}

- Studies to evaluate which stone formers are at most risk of bone disease.

- Studies to evaluate which treatment(s) for recurrent stones most favorably increase bone mass.

- Studies to evaluate which treatment(s) for osteoporosis in stone formers most favorably increase bone mass.

\section{Question \#5}

\section{Idiopathic calcium stone: how do we define it?}

A calcium stone former is considered to be idiopathic only after exclusion of the conditions listed in Table I. (Expert opinion)

Stone analysis of calcium stones allows one to refer more focused lists of conditions to be ruled out to secure the diagnosis of idiopathic stones (Table II). (Expert opinion)

To most, 'idiopathic calcium nephrolithiasis' means stones known or suspected to be made of calcium oxalate and/or hydroxyapatite without a systemic cause. Whether or not hypercalciuria is part of the definition is controversial. The relevance of this question is two-fold. First, diagnosing a stone patient as idiopathic means that a definitive treatment of a specific etiology, if available, cannot be offered to him; on the contrary, patients with idiopathic nephrolithiasis will be amenable only to a 'generic' pathophysiological treatment addressing life style, nutritional, and urinary risk factors. Second, how 'idiopathic stones' are defined is relevant to clinical research. In fact, studies may not be comparable if the definition of this prevalent condition differs between studies.

Idiopathic stone disease is a diagnosis of exclusion but individual practitioners' lists of known causes to be ruled out are not the same. Table 1 lists the criteria specifically indicated in articles by some of the Faculty members [20-29]. Note that few articles in the list address the calcium stone former with 'idiopathic hypercalciuria' [20-25]. The majority address generic 'idiopathic calcium stones' where the calcium nature of the stone has been ascertained by stone analysis or implied by radio-opacity. On the contrary, the precise stone 
composition is not generally a part of the definition of the phenotype. However, according to the Coe and Lingeman [21], idiopathic calcium stone formers should be restricted only to those forming predominant calcium oxalate $(\mathrm{CaOx})$ stones (with only a marginal amount of hydroxyapatite), while hydroxyapatite and brushite stone formers are distinct. The Faculty has agreed that hydroxyapatite stone formers and firsttime stone formers with some brushite in the stone should be investigated for systemic causes as well.

Table 1 Calcium nephrolithiasis: conditions to be ruled out in the idiopathic form

1. Hyperparathyroidism
2. Hyperthyroidism
3. Sarcoidosis
4. Vitamin D excess
5. Calcium supplements
6. Prolonged immobilization
7. Clinical evidence of bone disease
8. Malignant neoplasms
9. dRTA
10. MSK
11. Primary hyperoxaluria
12. Enteric hyperoxaluria
13. Bowel disease
14. Chronic pancreatitis
15. Vitamin C supplements
16. Chronic diarrhea
17. Lithogenic drugs
18. Urinary infection
19. Gouty diathesis
20. Cystinuria

This list is derived from [20-29]

dRTA distal renal tubular acidosis, MSK medullary sponge kidney
The list could be different and more focused if the precise stone composition is known, but if this is not available the extended list of 20 items (see Table 1) should be used. Note that this list and the following to be applied in specific conditions (Tables 2, 3) are mere opinion-based guidelines.

In reference to idiopathic $\mathbf{C a O x}$ stone disease, it is worth noting that this name represents a heterogeneous group of diseases, because a given patient may have 'idiopathic hypercalciuria', 'idiopathic hypocitraturia' or 'idiopathic hyperoxaluria', or none of these urinary risk factors.

The Faculty considered that it is reasonable to exclude the conditions listed in Table II in a stone practice. Since it is not possible or advisable to perform systematic genetic studies due to the rarity of these conditions, they should be ruled out only in those cases where there is clinical suspicion [30].

In reference to hydroxyapatite stones, hydroxyapatite is a frequent constituent of calcium stones. Its representation in a stone in a non-marginal quantity could suggest secondary forms of nephrolithiasis. The following conditions should be ruled out before concluding that a hydroxyapatite stone former is idiopathic: primary hyperparathyroidism, renal phosphate wasting conditions, medullary sponge kidney (MSK), complete and incomplete distal renal tubular acidosis (RTA) (see below, questions \#6 and \#7), abuse of absorbable antacids (calcium carbonate, the 'modern' form of milk alkali syndrome) and drugs inducing proximal RTA (carbonic anhydrase inhibitors).

In reference to brushite stones, their clinical phenotype has probably changed in recent decades. In case series recently described, the profile of the brushite stone former is one of a recurrent stone patient who had multiple previous extracorporeal shock wave lithotripsies (ESWL), and who may have converted from another stone composition such as calcium oxalate [31, 32]. Hypercalciuria is almost invariably present, but complete distal RTA and primary hyperparathyroidism

Table 2 Conditions to be excluded in idiopathic $\mathrm{CaOx}$ nephrolithiasis with hypercalciuria, hypocitraturia and hyperoxaluria

\begin{tabular}{lll}
\hline Conditions & Hypercalciuria & Hypocitraturia Hyperoxaluria \\
\hline Primary hyperparathyroidism & $\bullet$ & $\bullet$ \\
Prolonged immobilization & $\bullet$ & $\bullet$ (vit. D) \\
Incomplete dRTA & & $\bullet$ \\
Drugs and vitamin excess & & $\bullet$ \\
Chronic diarrhea & & $\bullet$ \\
Chronic pancreatitis, Crohn's disease, gastric bypass procedures, or small bowel \\
resections \\
Nephrocalcinosis \\
Genetic conditions associated with stones (including primary hyperoxaluria) \\
MSK
\end{tabular}

Abbreviations, see Table 1 
are not the cause [32]. The finding of obstructive lesions of the urinary tract, either congenital or acquired, is particularly notable in these stone patients [33]. The clinical phenotype is probably different in first-time stone formers with a brushite composition. Actually, in the older case series described by Pak et al.[34] distal RTA was frequently observed in brushite stone formers. Series suggest that idiopathic recurrent $\mathrm{CaOx}$ stone formers may switch to hydroxyapatite or brushite stones over time [35]. This is hypothesized to be the consequence of distal nephron damage induced by ESWL or previous obstructive episodes, or of preventive treatment with alkaline citrate [33-36]. In these hydroxyapatite or brushite patients, no investigation for systemic condition is warranted. On the contrary, in those patients who have passed brushite or apatite stones for the first time, systemic causes should be looked for.

The Faculty notes that the definitions used in this section are based on 24-h urine collection, although circadian variations in urine composition could be of great interest and value in the pathogenesis of idiopathic calcium stone disease.

\section{Future research directions}

- Studies on the pathogenesis of hypercalciuria

- Studies on the pathogenesis of brushite stones

- Studies on the relationship between ESWL and brushite stones

- Studies on circadian variation in urine composition

- Discovery of urinary markers of idiopathic calcium nephrolithiasis and metabolic activity

\section{Questions \#6 and \#7}

Should stone patients with an incomplete distal renal tubular acidosis be considered separately from idiopathic calcium stone formers?

Should incomplete distal RTA be searched for in all recurrent calcium stone formers?

Given the relatively high prevalence, the possibly associated conditions, as well as the therapeutic consequences, incomplete distal RTA should be distinguished from idiopathic calcium nephrolithiasis. (Expert Opinion)

Incomplete distal RTA should be searched for in recurrent calcium stone formers with hypocitraturia and less acidic urinary $\mathrm{pH}$ (fasting $\mathrm{pH}>5.8$ ) or unexplained recurrent hydroxyapatite nephrolithiasis or nephrocalcinosis. (Expert Opinion)

In the absence of rigorous comparative studies, the classical short $\mathrm{NH} 4 \mathrm{Cl}$ loading test $(0.1 \mathrm{~g} \mathrm{NH} 4 \mathrm{Cl} / \mathrm{Kg}$ body weight) with a cut off urinary $\mathrm{pH}$ of 5.3 should be used to diagnose incomplete distal RTA. (Expert Opinion)
The incomplete distal RTA is a condition where urinary acidification is defective but, at odds with the complete form, there is no systemic acidosis. Most incomplete distal RTA cases are not diagnosed in common practice because they are not even suspected or because of the complexity of the diagnosis that requires the classical short $\mathrm{NH}_{4} \mathrm{Cl}$ loading test. Incomplete distal RTA can be an acquired condition (e.g. nephrocalcinosis, MSK, Sjögren's syndrome, obstruction, repeated ESWL), but it is conceivable that incomplete distal RTA is in part due to allelic variants of genes recognized to cause the overt form. Indeed, in a family carrying an autosomal-recessive V-ATPase B1 subunit mutation, some heterozygous members were also affected by recurrent $\mathrm{CN}$ [37].

Different test types and durations, and varying cut offs for urinary $\mathrm{pH}$ for the definition of incomplete distal RTA have been proposed. However, due to lack of rigorous comparative studies, the validity of the different provocative test protocols in patients with (and without) recurrent $\mathrm{CN}$ is currently unknown. With this limitation, incomplete distal RTA prevalence seems to be present in between 2 and $21 \%$ of the general calcium stone forming population [38, 39]. Thus, incomplete distal RTA is a relatively frequent condition in recurrent $\mathrm{CN}$. As the stone composition changes from $\mathrm{CaOx}$ to mixed $\mathrm{CaOx}$-hydroxyapatite to pure hydroxyapatite, the prevalence of incomplete distal RTA increases from 5 to $40 \%$ [40]. Thus, incomplete distal RTA should be suspected in unexplained recurrent nephrolithiasis when stones are composed mostly or exclusively of hydroxyapatite; it should also be considered in recurrent calcium stone formers (either $\mathrm{CaOx}$ or hydroxyapatite) with hypocitraturia and less acidic urinary $\mathrm{pH}$ and in patients with nephrocalcinosis. Although no published data on 24-h urinary $\mathrm{pH}$ or fasting urinary $\mathrm{pH}$ in patients with incomplete distal RTA is available, the Faculty has agreed that in fasting urine a $\mathrm{pH}>5.8$ should suggest the possible existence of an incomplete distal RTA.

There are no RCTs for the prevention of stones in patients with incomplete distal RTA. In small studies, treatment with alkali citrate in adults with incomplete distal RTA decreased hypercalciuria, increased citraturia and reduced stone recurrence [41, 42].

\section{Future research directions}

- Clinical and basic studies in the area of incomplete distal RTA and in CN associated with incomplete distal RTA.

- Studies in which 24-h or fasting urinary $\mathrm{pH}$ should be used as a guide to indicate which stone formers should be tested for incomplete distal RTA.

- Studies on easier test protocols for diagnosing incomplete distal RTA. 


\section{Question \#8}

\section{How should hyperuricosuric calcium urolithiasis (HUCU) be diagnosed and treated?}

The diagnosis of HUCU is considered in a patient with mixed calcium oxalate and uric acid stones characterized by idiopathic hyperuricosuria, either in isolation or in combination with other risk factors for calcium stones (hypercalciuria, hypocitraturia, hyperoxalauria). (Expert Opinion)

In HUCU patients, allopurinol decreases stone events (Grade B - Standard).

The coexistence of $\mathrm{CaOx}$ and uric acid in urolithiasis has been noted repeatedly since the 1890s; Prien and Prien observed that gouty patients passed stones which contained or were composed of calcium oxalate; the first proposal that HUCU represents a novel syndrome was offered by Coe and Raisen in 1973 [43-45].

Since urine calcium and urine uric acid are correlated it should not be surprising that there exists a group of patients who have 'high' levels of both. Actually, epidemiologic studies of a large population of uncharacterized stoneformers failed to identify an independent association between urinary uric acid excretion rate and risk of all kidney stones [46]. On the contrary, earlier studies overlooked the fact that calciuria and uricosuria are not independently associated.

Indication of HUCU as a distinct entity mainly derives from the 'disputed' pathophysiological links between uric acid and $\mathrm{CaOx}$ crystallization [47-50]. Actually, several models have been proposed that are not mutually exclusive and can easily coexist. In fact, they can act in concert to cause $\mathrm{CaOx}$ crystallization. The models include the salting out of $\mathrm{CaOx}$ by urate in solution, the sequestration of various inhibitors of $\mathrm{CaOx}$ crystallization by colloidal uric acid, and heterogeneous nucleation or epitaxy of $\mathrm{CaOx}$ by uric acid/ urate crystals [50-55]. Results from trials with allopurinol also support the idea of HUCU as a distinct entity; in these studies the risk of calcium stones using hard clinical outcomes was lowered [44, 56-59]. However, it remains to be demonstrated that the favorable effect goes via a urinary urate lowering

Table 3 Conditions to be excluded in hyperuricosuric calcium urolithiasis

\begin{tabular}{ll}
\hline Overproduction & Renal leak \\
\hline $\begin{array}{l}\text { Gout/metabolic syndrome } \\
\text { Dietary purine overload }\end{array}$ & Uricosuric agents \\
Catabolic states & Rare transporter diseases \\
$\begin{array}{l}\text { Rare monogenic diseases } \\
\text { of purine metabolism }\end{array}$ & \\
\hline
\end{tabular}

effect. In view of the inconsistency of the definition of HUCU in older studies, the Faculty suggests a stricter definition of $\mathrm{HUCU}$, i.e. mixed $\mathrm{CaOx}$ and urate stones in the presence of hyperuricosuria with or without other risk factors for calcium stones. This definition of HUCU permits inclusion of risk factors such as hypercalciuria, hypocitraturia, and hyperoxaluria but with hyperuricosuria acting as a major driver of lithogenicity. Hyperuricosuria in these patients is idiopathic and other diagnoses leading to hyperuricosuria should be ruled out (Table III). The Faculty notes that most of the clinical evidence and therapeutic trials did not address HUCU as here defined, particularly in reference to stone composition. Thus, there is need to revisit this condition in view of the proposed definition.

\section{Future research directions}

- Studies on the exact physicochemical basis and on the relative contributions of each model.

- Development of the in silico way (akin to EQUIL or JESS) of quantitatively predicting the risk of calcium stones conferred by urine uric acid/urate.

- Studies on dose-effect of uricosuria on calcium stone risk.

- Studies on the degree of lowering uricosuria that should be targeted.

- Studies on the interaction of hyperuricosuria with other urinary stone risks.

- Studies on whether the threshold to treat and the therapeutic target differ depending on the presence and degree of hypercalciuria, hypocitraturia, and hyperoxaluria.

- Studies on the mechanism of the allopurinol stonepreventive effect.

- Therapeutic trial on HUCU as here defined.

\section{Question \#9}

Detection of systemic causes of nephrolithiasis - what is the best evaluation?

All stones should be analyzed for mineral composition. This alone will detect 3 important systemic causes of stone disease: cystinuria (cystine stones), adenine phosphoribosyltransferase (APRT) deficiency (dihydroxyadenine stones), and urease driven infection stones (struvite stones). Furthermore, it will detect stones induced by drugs. (Clinical Principle)

A standard urinalysis will provide an important screen for several systemic causes of stones: urinary tract infection (pyuria); Dent disease (proteinuria); cystinuria, and struvite stones (characteristic crystalluria). (Clinical Principle) 
A careful history can detect risk factors or clues for specific causes of stones: bowel resection or bariatric surgery (enteric hyperoxaluria [small bowel resection] or uric acid stones [ileostomy]); drug stones; and prolonged immobilization (hypercalciuria). (Clinical Principle)

Serum for creatinine, calcium, phosphorus, $\mathrm{K}, \mathrm{Mg}$, $\mathrm{HCO}_{3}, \mathrm{Cl}$, and uric acid will detect important factors that influence stone risk and/or treatment choices.

\section{(Clinical Principle)}

A 24-h urine test for creatinine, $\mathrm{pH}$, calcium, oxalate, citrate, uric acid, and qualitative cystine will detect major systemic causes of stone disease. If the panel is normal, a systemic cause is unlikely. If abnormal, a directed workup is indicated. (Clinical Principle)

All patients should have the composition of their urinary stones analyzed at least once. This is a cheap and valuable test that quickly identifies specific potential causes of stone disease. Importantly, a stone analysis alone can detect three important systemic causes of stone disease: cystine stones are diagnostic of cystinuria, dihydroxyadenine stones of APRT deficiency, and struvite stones of infection from a urease-positive organism. Other rare causes like drugs will also become apparent on a stone analysis.

A standard urinalysis with microscopy is an important screen for several systemic causes of stones. Pyuria suggests possible urinary tract infection. A high $\mathrm{pH}(>7.5)$ makes infection with a urease-positive organism possible, while a secondarily infected stone can be seen across the entire $\mathrm{pH}$ range. Proteinuria, especially in a male patient, makes it important to rule out Dent disease by confirming the nature of the proteinuria (i.e. screen for low molecular weight proteins like retinol binding protein, alpha-1 microglobulin, or beta-2 microglobulin). Crystals of cystine, dihydroxyadenine, and struvite are also characteristic in appearance, and these diagnoses can be confirmed with other tests.

A careful history is an essential part of a urinary stone evaluation. A history of any form of gastrointestinal disease suggests possible specific risk factors. Diseases that affect the small intestine or pancreas, including Crohn's disease, gastric bypass procedures, or chronic pancreatitis, often lead to fat malabsorption and enteric hyperoxaluria. Gastrointestinal diseases that are associated with chronic diarrhea also cause excessive loss of bicarbonate in the stool and hence an appropriately low urinary $\mathrm{pH}$, which raises the risk of uric acid stones. An intact colon is necessary for enteric hyperoxaluria. Hence, conditions with large gastrointestinal losses of fluid without a colon, e.g. the presence of an ileostomy, are typically associated with uric acid and not $\mathrm{CaOx}$ stones. Finally, certain fairly rare disorders such as sarcoidosis, or prolonged immobilization are associated with rapid loss of bone calcium and hypercalciuria.

A serum test for creatinine, calcium, phosphorus, $\mathrm{K}, \mathrm{Mg}$, $\mathrm{HCO}_{3}, \mathrm{Cl}$, uric acid can effectively screen for important risk factors that influence stone risk factors and/or treatment choices. Hypercalcemia is an important sign of hyperparathyroidism, as well as rare conditions such as CYP24A1 mutations or sarcoidosis. A low serum phosphorus is also consistent with hyperparathyroidism. A low potassium can contribute to hypocitraturia and/or suggest RTA, while a low serum bicarbonate suggests chronic gastrointestinal losses or RTA. An elevated serum creatinine suggests $\mathrm{CKD}$, which can influence the choice of treatments like potassium citrate.

Systemic causes of urinary stone disease are associated with predictable urinary abnormalities. Hence, a 24-h urine for creatinine, $\mathrm{pH}$, calcium, oxalate, citrate, uric acid, and qualitative cystine is useful to detect major causes of stone disease. For example, a low urine $\mathrm{pH}$ and low urine citrate suggests gastrointestinal base losses, and a high urine $\mathrm{pH}$ and low citrate indicates possible RTA. Hyperoxaluria makes it important to consider enteric or primary hyperoxaluria, and hypercalciuria makes it essential to consider a systemic disease of calcium metabolism. Conversely, if all elements of the 24-h urine are normal, a systemic cause of stone disease is less likely.

\section{Future research directions}

- Studies on the performance of different diagnostic algorithms in identifying secondary forms of nephrolithiasis.

\section{Question \#10}

\section{Is the measurement in urine of some index of} lithogenic risk clinically useful?

The overall lithogenic risk cannot be estimated in urine. The best approximation is the determination of the upper limit of metastability (ULM). However, ULM measurement is only suitable for research purposes. (Expert Opinion)

Determination of the relative supersaturation (RS) could be useful to improve patient's compliance to preventive treatment of calcium nephrolithiasis. (Expert Opinion)

Relative supersaturation (RS) of urine for calcium containing stone-forming species is the essential condition for a stone to form. RS can be easily estimated with a dedicated algorithm (Equil, JESS, Lithorisk). However, RS 
does not fully represent the overall lithogenic risk since it fails to estimate the inhibitory potential of urine and of the cells-crystal interaction in the renal tubule. There are no available data from pharmacologic RCTs with follow-up and treatment guided by urine supersaturation levels; hence, it is not established whether changes in urine supersaturation measurements predict reduced risk of recurrent stones with drug treatment. However, experts believe that measuring RS levels during follow-up may be a useful tool for increasing patient compliance.

The ULM is defined as the value of RS where spontaneous crystallization in urine occurs. It is different from RS because it is influenced by the inhibitory potential of urine. However, it still does not estimate the contribution of the cells-crystal interaction. Furthermore, ULM determination is time-consuming and not standardized.

\section{Future research directions}

- Studies on standardization of methods for ULM determination and application to larger numbers of stone forming and non-stone forming subjects.

- Studies investigating whether follow-up and treatment guided by urine RS determination decreases stone recurrences.

\section{Question \#11}

Is the observation of the urine sediment clinically useful in calcium stone formers?

In calcium stone disease, analysis of crystalluria is of limited clinical value in the diagnostic workup, and is not recommended for treatment follow-up. (Grade $C$ Recommendation)

A major limitation of studies of crystalluria is the lack of standardization since urine can be examined fresh or stored, collected after fasting or as a 24-h study, centrifuged or evaporated, and quantified by coulter counter or microscope.

Studies in patients with $\mathrm{CN}$ have addressed frequency, composition, size and volume, agglomeration and attachment of crystals. Using fresh voided urine, it was found that crystalluria was more prevalent in calcium stone formers than in controls, but the type of crystals did not differ [60]. The type of $\mathrm{CaOx}$ crystals (whewellite vs. weddellite) seems to discriminate to a degree between hyperoxaluric and hypercalciuric stone formers [61]. Volume of crystals was higher in stone formers $[62,63]$. However, crystal presence was not modified by different treatments even though the type of crystals changed from more calcium phosphate to more $\mathrm{CaOx}$ [60]. Presence of crystals was poorly related to degree of supersaturation [63].
Crystal agglomeration was more frequent in stone formers but of low incidence (1.4-8 \%).

Inhibition of stone agglomeration exhibited some correlation with efficacy of treatment [64].

\section{Future research directions}

- Crystal aggregation (agglomeration) and crystal-cell interaction may be of clinical use in the future. At present, data are too scarce. For a better understanding of the mechanism of stone formation, it may be worthwhile to combine urine crystal analysis with endoscopic analysis of papilla, correlating it with the presence of plaques and plugs.

\section{Question \#12}

Is measurement of crystallization inhibition in urine
of clinical value?
Measuring inhibition of crystallization and crystal
aggregation in urine is not recommended since
methods are cumbersome and the only way to
manipulate it, i.e. the administration of citrate, is
decided on the direct measurement of citraturia. (Grade
C- Recommendation)

This question is flawed by the lack of a clear demonstration of a role of crystallization inhibitors and crystal aggregation inhibitors in $\mathrm{CN}$. Furthermore, clinical value could only be obtained if:

1. it is known which inhibitors that affect the relevant processes differ between people who do vs. do not form stones,

2. measuring this difference can be done in a high throughput manner, and

3. the inhibitory action can be manipulated.

Studies on crystallization inhibition/inhibitors are numerous. However, they often lack standardization or were not designed to exactly mimic the environment where stones are thought to form by the two mechanisms described above. Study quality is low to moderate. The majority of studies dealt with individual urine compounds. Only a few studies include comparison of a stone former group to a control group. Even fewer studies actually compare inhibitory action of urine between the two groups. No studies were found that apply conditions resembling the renal interstitial fluid.

With respect to crystal growth, the results of the comparison between people who do or do not form stones are not uniform and only suggest the following expert opinion: urine contains many compounds that can 
inhibit crystal growth. In urine, macromolecules with an affinity for calcium deliver most of the growth inhibition capacity. However, when these compounds are lacking in quantity or function their action is taken over by other inhibitors that are also present in the urine. This overload of growth inhibitors may explain why crystal growth inhibition does not differentiate stone formers from controls.

With respect to crystal aggregation (or agglomeration) fewer studies are available but the conclusion is more uniform $[65,66]$. Stone formers produce larger particles, mainly aggregates, and their urine is less able to inhibit crystal aggregation. Some studies show a correlation between the severity of the disease, expressed as number of stones formed per patient, and capacity to inhibit aggregation. This capacity seems to be exerted both by an interplay between macromolecules and small molecules like citrate [66]. Interventions that aim to increase the urine citrate content also increase the aggregation inhibition. There is no standardized method to measure crystal aggregation inhibition by whole urine in a high throughput method.

\section{Future research directions}

- Studies on the role of crystallization inhibitors and crystal aggregation inhibitors in stone formation in the interstitium (Randall's plaque precursors), and in the interface with papillary deposits (Randall's plaque), and ductal plugs.

\section{Question \#13}

Are surgical observations during stone treatment potentially useful for the diagnosis and prognosis of nephrolithiasis?

The endoscopic evaluation of papillae in stone formers could provide valuable information in the diagnostic workup of stone formers, and a scoring system for papillary pathology in stone formers has potential utility in diagnosis and prediction of prognosis of disease. (Expert Opinion)

Recent studies that have utilized endoscopy and papillary biopsy for the study of stone patients have revealed that stone formers differ not only in the types of mineral that they deposit in their stones $(\mathrm{CaOx}$, brushite, struvite, etc.) but also in the pathology of their renal papillae with regard to the presence of Randall's plaque and ductal plugging [26, 27, 33, 67-74]. Moreover, there is at least some correlation between the histopathologic pathologies observed in a papillary biopsy and the visual appearance of the same papilla before biopsy [75]. Thus, although stone formers have classically been divided by the minerals contained in the stones that they form [76], the possibility exists that this classification could be improved-or perhaps even replaced-by endoscopic observations during minimally invasive removal of renal stones.

The consensus of the working group was that endoscopic evaluation of papillae in stone formers could definitely have value, and that a scoring system for papillary pathology in stone formers has potential utility in diagnosis and prediction of prognosis of disease. We note that the first publications of a papillary scoring system have recently emerged [77-79].

Study of the utility of a papillary scoring system in stone formers calls for correlation with prognosis of disease and prediction of recurrence of stones. There is already some evidence for the correlation of papillary computed tomography (CT) density (which is increased by the presence of small stones or ductal plugs [80]) with stone recurrence rates [81]. Endoscopic observation of papillary pathology is more informative than CT [80], and thus logically could be more predictive of stone recurrence. Similarly, evidence for the connection of stones with CKD [82, 83] may well be informed by papillary pathology, as the plugging of collecting ducts is a probable cause of kidney injury. Finally, the working group was convinced that evaluation of papillary pathology endoscopically also could have the potential to indicate the direction of metabolic diagnosis and treatment for a given patient [84].

\section{Future research directions}

- Development of papillary scoring systems, including validation by external observers, with subsequent study of the utility of each scoring system in clinical practice.

- Studies of the correlation of papillary pathology with prognosis of disease and prediction of recurrence of stones.

\section{Question \#14}

Is stone analysis and stone morphology of clinical utility?

Stone analysis should be done with modern methods, either infrared (IR) spectroscopy or X-ray diffraction. Since stone composition can change in a patient over time, stone analysis should be done regularly and in a standardized fashion. (Clinical Principle)

More work needs to be done before stone morphology can be added to standard stone analysis. (Expert Opinion) 
Stone analysis is not uniformly well done around the world - or even uniformly well done within countries [85, 86]. Thus it is not surprising that data on stone composition have not been correlated well with patient outcomes. This is especially true for stone analysis done by wet chemical methods, where the errors inherent within such analyses $[85,87]$ would certainly preclude any ability to identify relationships between stone components and patient characteristics.

But even with the use of modern spectroscopic methods of analysing stone mineral, the existing practice has limitations. For example, evaluation of the composition of mixed stones relies on skilful dissection of the specimen, which may not always happen [86]. There are also several reports that suggest that the recognition of special stone morphologies can be pathognomonic for certain conditions [88-90], but there is no evidence that these morphologies are being widely recognized in analysis practice.

Although progress is being made in the use of dualenergy CT to identify stone composition [91], it is unlikely that this will ever replace stone analysis, as the spatial resolution required to assess stones of multiple components is quite fine [92]. Thus, the working panel concluded that work needs to be done to improve existing practices of stone analysis. Even though a detailed model for proper stone analysis exists, this model needs to be emulated by other sites. There is much need for education, as methods across countries are not consistent, and there are few practices for testing that are widespread [93]. In addition, the nomenclature for stone components needs to be standardized [86].

The working panel was convinced that stone analysis should be done, and because stone composition can change in a patient over time [94, 95], it should be done regularly and in a standardized fashion. In addition, although rare stones are indeed rare, stone analysis is inexpensive and delay in recognizing a rare stone in a patient can lead to loss of kidney function that would have been preventable if the rare stone had been recognized upon first presentation [96]. Although the panel was convinced that observation of stone morphology has potential utility, it concluded that more work needs to be done before this can be added to standard stone analysis.

\section{Future research directions}

- Educational work needs to be done to improve existing practices of stone analysis.

- Nomenclature for stone components needs to be standardized.

- More work is needed on stone morphology to implement it in stone analysis.
Questions \#15, \#16 and \#17

\section{Who is the recurrent calcium stone former? How should metabolic activity be determined? How should calcium stone formers be evaluated?}

A single calcium stone former is a patient who seeks advice for a single, solitary kidney stone episode and who has no other stones seen by imaging in the kidney. A recurrent calcium stone former is a patient with multiple kidney stones, which can occur at the same time or be temporally spaced. Metabolically active stone disease is identified by new stone formation or stone growth on serial imaging. Yet, the underlying disorder can only be identified by performing a comprehensive metabolic evaluation. Studies suggest that metabolic activity will persist, but can be controlled with dietary or medical management.

\section{(Expert opinion)}

The recurrent stone former, and the single stone former, whenever considered at high clinical risk for recurrence (younger age, family history of nephrolithiasis, etc.), should be evaluated comprehensively, including preferably two 24-h urine studies on a random diet at least 3-4 weeks after stone passage or treatment. (Grade B - Standard)

The distinction between single and recurrent stone formation is usually based on clinical evidence of either isolated or multiple episodes of stones, but this definition is not precise. Imaging studies complement the definition of stone recurrence. Stone recurrence and/or growth are indications of 'metabolic activity'. The concept of metabolic activity of stone disease means the existence of an ongoing crystallization-driving process that most likely will lead to new stones or to the growth of already existing stones. It is the concept of metabolic activity that should ideally drive the clinician's decision on how to treat the stone patient. Single and recurrent stone formers share many similarities in their metabolic profiles [97, 98]. There are no markers that may distinguish between single and recurrent stone formers and metabolically active vs. metabolically inactive stone formers. A nomogram (ROKS) for the prediction of a second (recurrent) symptomatic stone episode has been recently proposed [99]. However, only symptomatic stones were considered and the 10 years recurrence rate was only $30 \%$ on the whole, and no more than $56 \%$ in the subgroup of patients at highest risk. The evaluation of the stone patient should also address the patient's risk factors for recurrent stone formation or other morbidities and indications. These risk factors and conditions include, but are not limited to, family history of stone formation; pediatric age; solitary kidney; patients with concurrent medical conditions; nephrocalcinosis, CKD or skeletal diseases; history of bowel disease or bowel surgery; patient's 
job (i.e. pilots, frequent business travelers); difficult to treat stones (e.g. urinary tract abnormalities/reconstruction); and immuno-compromised conditions.

\section{Future research directions}

- Studies on markers that predict stone recurrence.

- Studies on metabolic markers that distinguish metabolically active vs. metabolically inactive stone formers.

\section{Questions \#18 and \#19}

\section{Should we follow patients with non-active idiopathic calcium nephrolithiasis and how?}

How do we follow patients with calcium nephrolithiasis under preventive treatment?

Single stone formers without clinical risk for recurrence should be offered an initial simplified metabolic evaluation and a clinical follow-up. According to the level of metabolic activity presented during this follow-up or to changes from the initial presentation the clinician should perform a more thorough and frequent follow-up. (Expert opinion)

A follow-up 24-h urine collection should be repeated after 3-6 months from the start of selective medical therapy, to assess response to dietary and/or medical therapy or for adverse effects. Metabolic follow-up thereafter can be performed yearly to assess the effectiveness and adherence to medical therapy. More frequent follow-up is recommended based on stone composition, such as in brushite stone formers; patients with recurrent or multiple stones; those with a family history of stone formation; patients with difficult to treat stones; children with calcium stones; stone formation in a solitary kidney; patients with concurrent medical conditions; individuals with CKD or nephrocalcinosis or skeletal diseases; and those with a history of bowel disease or bowel surgery. Other relative indications for a more frequent follow-up include: those patients whose job requires they be without stones (i.e. pilots, frequent business travelers); patients with difficult to treat stones (i.e. urinary tract abnormalities/reconstruction); and individuals who are immuno-compromised. (Expert Opinion).

Periodic imaging performed annually allows for an assessment of clinical activity, defined as new stone formation or stone growth, though the timing and type of imaging can be tailored based on stone composition, activity and location (renal or ureteral), as well as clinical signs and symptoms. DXA should be repeated over time, whenever osteopenia or osteoporosis is detected on the metabolic evaluation (Expert Opinion).
Follow-up is the mainstay of conservative and active management of $\mathrm{CN}$, to prevent both stone growth and new stone formation. The greatest challenge in following stone formers is their low adherence to conservative or selective medical recommendations, particularly dietary advice. The purpose of follow-up is to assess the efficacy of treatment, to encourage patient compliance and ultimately reduce the risk of stone recurrence. Through close monitoring, the clinician is able to assess treatment adherence to or effectiveness of recommendations, allowing adjustment of pharmacological treatment dosing and the determination of both short- and long-term adverse effects of directed medical therapy. However, continued management of patients with stone disease varies widely between practitioners, since no studies have assessed an optimal schedule as the primary outcome. Despite the lack of evidence-based principles, systematic reviews of the literature and recently published guidelines help to establish which laboratory or imaging studies should be performed, their frequency and duration, and also to define the target population: single and/or recurrent stone formers $[1,2]$.

\section{Future research directions}

- Studies on the fate of asymptomatic stone formers. Should patients with renal stone(s) incidentally found in imaging studies undergo a metabolic evaluation and/ or follow-up?

- New stone formation and stone growth are not always distinguishable depending on different imaging modalities. Future observational studies or RCTs should employ sensitive and, more importantly, standardized detection methods. They should define an absolute stone size or growth rate threshold(s) in order to ascertain the presence of baseline residual stones, and then to establish measurement of stone growth. The use of standard modalities and appropriate testing frequencies, to ascertain incident radiographic stones should be defined. Patients with asymptomatic stone growth, radiographic stone recurrence and/or asymptomatic stone passage should be followed untreated for several years for symptomatic stone recurrence to help determine whether and under what circumstances these measures can serve as appropriate surrogates for symptomatic stone recurrence. RCTs should separately report the outcomes of symptomatic and radiographic stones, describe the laboratory and radiographic testing that participants undergo, including their cumulative radiation exposure. 


\section{Question \#20}

Is any special beverage likely to matter apart from being a way to provide water?

Patients with calcium nephrolithiasis should maintain a fluid intake sufficient to achieve a urine volume of at least 2.0 to 2.5 1/d. (Grade $\boldsymbol{A}$ - Standard)

Reduced sugar-sweetened soft drink intake lowers recurrence risk in patients with high baseline consumption. (Grade B - Standard)

The intake of orange juice with no added sugar might confer protection toward calcium nephrolithiasis. (Grade C - Recommendation)

A low urine volume is one of the most important risk factors for urinary stone formation. One RCT showed that idiopathic $\mathrm{CaOx}$ stone formers who increased fluid intake to maintain a urine volume of greater than 2 1/day had a significantly lower recurrence rate during the 5-year follow-up period than the control group (12.1 vs. 27.0\%, p =0.008) [100]. Another trial in $\mathrm{CaOx}$ stone formers who became stone free after shock wave lithotripsy found a decrease in stone recurrence in patients with increased fluid intake to achieve more than 2.51 of urine per day compared with no treatment for 2-3 years (8.3 vs. $55.6 \%, \mathrm{p}<0.05)$ [101].

By contrast, there is unfortunately no hard data on the importance of water composition. In both healthy subjects and patients with recurrent $\mathrm{CaOx}$ urolithiasis, an elevated intake of mineral water with a very high bicarbonate and magnesium content (28 and $44 \mathrm{mEq} / \mathrm{l}$, respectively) was shown to produce higher urinary citrate and magnesium excretion compared to an equal amount of control water and to significantly alkalinize urine $[102,103]$ : nevertheless, the observed decrease in urinary super-saturation for $\mathrm{CaOx}$ was comparable to that obtained with the control water and mostly due to the increase in urine volume, whereas supersaturation for calcium phosphate was significantly increased due to the significant rise in urinary $\mathrm{pH}$.

Most controlled clinical trials testing the effect of water with a high calcium content in calcium stone patients observed increases in urinary calcium excretion paralleled by a decrease in urinary oxalate excretion, presumably due to increased oxalate complexation by calcium in the gut and subsequent reduced intestinal absorption of free oxalate. However, the long-term effect on stone recurrence rate is unknown [104].

A prospective observational study on three large cohorts of individuals without a history of nephrolithiasis found that the risk of incident kidney stones was directly associated with consumption of sugar-sweetened beverages and inverse associations with the intake of orange juice but also with the consumption of both caffeinated and decaffeinated coffee, tea, beer and wine [105]. In a large RCT in stoneforming men with a high baseline sugar-sweetened beverage consumption, abstinence from soft drink intake significantly reduced the risk of recurrence at 3 years compared to the control group (33.7 vs. $40.6 \%$, $\mathrm{p}=0.023$ ) [106].

Overall, there is sound evidence against the consumption of sugar-sweetened beverages and circumstantial evidence in favour of orange juice intake with no added sugar for prevention of $\mathrm{CN}$.

\section{Future research directions}

- Controlled trials of the effects of different types of beverages, including bicarbonate-rich mineral water and water with different calcium content, on the rate of stone recurrence in patients with $\mathrm{CN}$ are warranted.

\section{Question \#21}

Do diet treatments prevent calcium oxalate stones?

Any recommendation for prevention of calcium nephrolithiasis should be seen in the framework of a well-balanced healthy diet that is also effective for the prevention of major chronic degenerative disorders. (Expert Opinion)

Dietary intervention should be based on the assessment of the patient's habitual diet and the identification of specific metabolic risk factors, if any, for calcium oxalate nephrolithiasis. (Expert Opinion)

Calcium-oxalate stone formers with hypercalciuria should maintain a dietary calcium intake not lower than $1000 \mathrm{mg} /$ day, a sodium intake not higher than 2.4 $\mathrm{g} /$ day (or $6 \mathrm{~g}$ of salt) and a moderate intake of nondairy animal protein (i.e. $0.8 \mathrm{~g} / \mathrm{kg}$ body weight or less (Grade A - Standard).

Calcium-oxalate stone formers with high urinary oxalate excretion benefit from a normal dietary calcium intake and reasonable limitation of selected oxalate-rich foods. (Grade C - Recommendation)

Calcium-oxalate stone formers with low urinary citrate excretion should increase their intake of fruits and vegetables and limit non-dairy animal protein. (Grade C - Recommendation)

Vitamin C supplementation increases the risk of calcium nephrolithiasis (Grade B - Standard).

Combined Vitamin D and calcium supplementation may increase the risk of calcium nephrolithiasis; thus, when needed, it should be prescribed with periodic monitoring of urinary calcium excretion. (Grade $C$ Recommendation) 
An observational study supports the idea that the Dietary Approaches to Stop Hypertension (DASH) diet, an example of dietary model designed for the prevention of cardiovascular diseases, may be effective also in primary prevention of CN [107]. The Mediterranean diet [108] and the lacto-ovo vegetarian models [109] are other examples of healthy well-balanced diets with many features potentially effective for the prevention of $\mathrm{CN}$.

It has been recognized that dietary recommendations tailored to the specific patient condition are more likely to be effective than non-specific dietary advice in preventing recurrences [110].

An RCT showed that an interventional diet consisting of normal calcium, low sodium and low animal protein content, associated with high fluid intake, effectively reduced the rate of stone recurrence as compared to high fluid intake associated with a low calcium diet [20]. In addition, high quality prospective studies showed that a normal dietary calcium intake (1000-1200 mg/day) for most adult individuals is associated with a reduced risk of stone formation compared to lower intakes [111-116]. Both clinical [117] and epidemiological studies [118] suggest to reduce sodium intake since the higher the salt intake, the greater the calcium excretion [119].

Large high quality cohort studies in the general population have demonstrated an inverse relationship between dietary calcium intake and urinary oxalate excretion $[111,120,121]$. When the recommended intake of calcium was achieved, even a relatively high dietary oxalate intake was not associated with higher $\mathrm{CaOx}$ stone risk [120]. Although these studies did not target recurrent $\mathrm{CN}$ patients, it is conceivable that patients with hyperoxaluria and a history of $\mathrm{CaOx}$ stones would also benefit from a relatively high calcium intake (1000-1200 mg/day) on the same grounds. As the urinary oxalate excretion is significantly related to the amount of oxalate in the $\operatorname{diet}^{120}$, a limited consumption of selected oxalate-rich foods is advisable in these patients. On the other hand, extreme restriction of dietary oxalate is impractical and possibly dangerous as it would result in lower intakes of fruits, vegetables and whole grains which are known to provide other major health benefits $[120,121]$.

A fruit and vegetable rich diet significantly increases the urinary citrate and phytate excretion [122] and was found to be protective against $\mathrm{CN}$ in a number of good quality observational prospective studies [20, 107, 123]. By contrast, a high dietary acid load reduces urinary citrate [124] and a good quality observational prospective study has shown that fish and poultry proteins are associated with increased risk of first-stone formation as opposed to vegetable and dairy proteins [125]. Thus, patients with hypocitraturia should be instructed to reduce non-dairy animal protein intake.
The results of good quality population-based prospective studies are consistent with a higher risk of $\mathrm{CN}$ in males taking vitamin $\mathrm{C}$ supplements $[126,127]$. There is also circumstantial evidence in post-menopausal women that combined intake of vitamin D and calcium supplements increases the rate of incident $\mathrm{CN}$ [128].

\section{Future research directions}

- RCTs on the value of complex dietary patterns, such as the Mediterranean diet, in primary and secondary prevention of nephrolithiasis are warranted.

\section{Questions \#22, \#23 and \#24}

When to use citrate?
When to use thiazides?
When to use oral phosphate?
Potassium citrate is indicated in recurrent $\mathrm{CaOx}$ and
calcium phosphate stone formers with: 1) low or
relatively low urinary citrate excretion; 2) complete or
incomplete distal RTA, chronic diarrheal states, drug-
induced or diet-induced hypocitraturia, and 3)
osteopenia/osteoporosis. (Grade B - Standard)
Thiazides are appropriate for both CaOx and calcium
phosphate stones in hypercalciuric stone formers, and
even in normocalciuric patients when dietary measures
and increased fluid intake have not prevented stone
recurrence. (Expert Opinion)
There is no evidence supporting the use of any
phosphate supplement in the treatment of idiopathic
calcium nephrolithiasis. (Expert Opinion)

The relative merits and drawbacks of citrate and thiazides in stone prevention are well known but they have not been compared head-to-head in any trial. Discussion of the risks and benefits of both treatments should ensue with patients, whose values should be taken into consideration.

Citrate inhibits crystallization processes in calcium stone formers. Potassium citrate is therefore indicated for the following clinical situations: (1) recurrent $\mathrm{CaOx}$ and calcium phosphate stones with low or relatively low urinary citrate excretion; (2) patients with complete or incomplete distal RTA, chronic diarrheal states, drug-induced or diet-induced hypocitraturia [41, 42, 129-131], and known osteopenia or osteoporosis. In case of intolerance to citrate, potassium bicarbonate can be used instead. Sodium citrate should be avoided because sodium promotes calcium excretion and is less effective at promoting citrate excretion than potassium salts [132].

Thiazide diuretics should be offered to patients with high or relatively high urine calcium and recurrent calcium 
stones [133-138], although the precise mechanism of thiazide action has not been elucidated. The AUA guidelines [1] also suggest that thiazides would be useful in patients without relatively high urine calcium excretion as lowering urine calcium excretion may be effective regardless of the absolute rate of calcium excretion. Some studies showing efficacy of thiazides did not require hypercalciuria at baseline. Thiazides would be appropriate when dietary measures and increased fluid intake have not prevented stone recurrence. Under these circumstances, thiazides are considered appropriate for both $\mathrm{CaOx}$ and calcium phosphate stones. Appropriate doses and regimens include hydrochlorothiazide $25 \mathrm{mg}$ twice a day, chlorthalidone $25 \mathrm{mg}$ once a day or indapamide $2.5 \mathrm{mg}$ once a day. Thiazides should always be administered with potassium to avoid increased cardiovascular risk and minimize glucose intolerance [139, 140]. Potassium citrate supplementation may be preferred to potassium chloride to maintain urinary citrate excretion, improve bone mineral density and reduce urinary calcium excretion. Alternatively, potassium loss can be counteracted by amiloride $5 \mathrm{mg}$ or spironolactone 25 or $50 \mathrm{mg}$. Triamterene should be avoided.

Both citrate and thiazides appear to increase bone mineral density, a frequent correlate of hypercalciuria and calcium stones. Possibly these effects are synergistic though the combination has not been specifically tested. Thiazides may be considered the blood pressure lowering drugs of choice in patients with kidney stones as they have consistently been shown to be the preferred agents for the treatment of essential hypertension, systolic hypertension, and hypertension in the elderly because of their consistent effect to lower cardiovascular morbidity and mortality.

Treatment with oral phosphate results in reduction in urinary calcium excretion largely due to inhibition of calcitriol synthesis [141]. One main concern with oral phosphate administration has been the possibility of metastatic soft tissue calcifications resulting in renal functional impairment. One long-term, blinded controlled study in a small number of absorptive hypercalciuric kidney stoneforming subjects using sustained released potassium phosphate showed the safety of this preparation [142]. However, the efficacy was not tested in a multicenter trial using incident kidney stone episode as an outcome.

\section{Future research directions}

- RCTs on the pharmacological prevention with thiazides of recurrent calcium stone disease with different biochemical phenotypes (normo- and hypercalciuric, etc.).

- Since the pharmacological armamentarium for renal stone prevention is quite limited there is need of studies investigating new drugs to prevent stone recurrence.

\section{Question \#25}

Is the use of citrate safe in reference to the risk of calcium phosphate lithogenesis during calcium oxalate stone prevention?

The use of citrate treatment in patients with calcium oxalate stones is safe provided that the urinary citrate increase is commensurate with the rise in urinary $\mathrm{pH}$.

(Expert Opinion)

In two open trials in patients with distal RTA and MSK prone to calcium phosphate stone formation, citrate treatment significantly reduced the prevalence of kidney stones [41, 42]. However, in one retrospective study it was shown that those who transformed the stone composition to calcium phosphate stones had a higher baseline and post treatment urinary $\mathrm{pH}$ compared to non-transformers [143]. Due to the sparsity of controlled studies delineating the risk of calcium phosphate stone formation with alkali therapy, alternatives to alkali treatment should be tested in prospective clinical studies. Until such a study is performed, clinicians should offer citrate treatment to patients with calcium phosphate stones in whom urinary citrate increases commensurate with a rise of urinary $\mathrm{pH}$.

\section{Future research directions}

- Due to the potential risk of calcium phosphate stone formation with alkali treatment, alternatives to alkali treatment should be tested in prospective clinical studies using citric acid vs. potassium citrate or thiazide + potassium chloride vs. thiazide + potassium citrate in this population.

\section{Questions \#26 and \#27}

\section{When should the urologist and the nephrologist collaborate?}

How should such a cooperation be implemented?

Before elective surgery:

Collaboration between urologists and nephrologists is advocated for the assessment of the etiology of renal stones in order to prevent sudden relapses in secondary forms of nephrolithiasis and in patients with advanced renal failure for the evaluation of the risk-benefit ratio of the intervention. (Expert Opinion)

Either before or after elective surgery:

Collaboration between urologists and nephrologists is advocated in patients with severe stone disease, or those with a putative high risk of recurrence where a comprehensive diagnostic workup or the expertise are 
not available in urology; furthermore, it is advocated in patients with CKD or at risk of CKD, single kidney, anatomical urinary tract abnormalities, and in patients with infected stones. (Expert Opinion)

Collaboration can be enhanced on a local level by Multidisciplinary Stone Meetings (educational and for discussion on active clinical cases), local protocols and guidelines, and joint stone teams. (Expert Opinion)

Nephrologists and urologists have been working side by side for a very long time. Yet, too often, there seems to be a rivalry, almost a competition, as can be found in many places between physicians and surgeons. Naturally, given the different approaches to disease, their view of the world and even their 'dialects' differ [144]. This poses a barrier between the two specialties that applies also to stone disease, which is often complex and caused by certain underlying co-morbidities that cannot be tackled by blasting the stone alone. Conveniently, though, for the urologists, developments in stone blasting technologies have made treatment very smooth and easy, leading to a neglect in looking for the diagnosis of underlying causes. On the other hand, nephrologists show only a limited interest in stone disease amongst all the other renal pathologies they have to deal with.

We believe that in the clinical management of patients with nephrolithiasis, the collaboration between nephrologists and urologists is crucial. A close collaboration based on each other's understanding is needed not only during the acute phase of stone-related renal injury, but also during the clinically stable phase of the disease. However, in a global perspective this principle is not generally applicable and it needs to be emphasized that such a shift in routine cannot be accomplished without a change in the education of nephrologists. In a survey of urologists performed before the conference to obtain a better picture of their urologists' point of view, $51 \%$ of respondents claimed to refer stone formers to nephrologists "occasionally" and, more worrisome, $39 \%$ said "never". Yet, secondary and metabolic stone disease were the main reasons for referral to the nephrologist.

Currently, we are not aware of any guidelines for urologists regarding nephrology referrals. A recent study shows a poor implementation of guidelines among healthcare providers [145], and we may assume this to be true for urologists and nephrologists as well. Searches in literature databases for such guidelines using an array of search terms did not reveal any hits.

\section{Future research directions}

- As part of an integrated clinical management pathway for nephrolithiasis patients, the nephrologist and urologist-ideally in collaboration-will have to face the development of shared protocols for the evaluation of stone formers and for defining cooperation.

- The evaluation of Quality and cost/benefit ratio of the protocols for renal stone forming patients.

- Cost/benefit analysis of instrumental investigations for the follow-up of renal stone forming patients (economic cost, radiological risks).

Acknowledgments This article is based on the results of the "Consensus Conference for the metabolic diagnosis and medical prevention of calcium nephrolithiasis and its systemic manifestations", Rome, March 26-28, 2015 which was generously supported by International Foundation Menarini, Milan, Italy with an unrestricted educational Grant.

Consensus Conference Group Bartoletti R, Dept of Translational Medicine and New Technologies, University of Pisa, Pisa, Italy; Buchholz N, Sobeh's Vascular and Medical Center, Department of Urological Surgeon, Dubai, UAE; Bushinsky D, University of Rochester, Medical Center, Department of Nephrology, Rochester, USA; Capasso GB, University of Naples, Dept. of Medicine, Naples, Italy; Cicerello E, General Hospital Ca' Foncello, Department of Urology, Treviso, Italy; Coe F, University of Chicago, Medicine, Department of Nephrology, Chicago, USA; Croppi E, A.S.L. 10, Florence, Italy; Cupisti A, University of Pisa, Department of Nephrology, Pisa, Italy; Curhan GC, Brigham and Women's Hospital, Renal Division, Boston, USA; Desai J, Samved Hospital, Department of Urology, Ahmedabad, India; Fabris A, Maggiore University Hospital, Department of Nephrology, Verona, Italy; Ferraro PM, Catholic University of the Sacred Heart, A. Gemelli University Hospital, Department of Nephrology and Dialysis, Rome, Italy; Fuster D, University of Bern, Department of Nephrology, Bern, Switzerland; Gambaro G, Catholic University of the Sacred Heart, A. Gemelli University Hospital, Department of Nephrology and Dialysis, Rome, Italy; Goldfarb DS, New York Harbor VA Health Care System, Department of Nephrology, New York, USA; Heilberg IP, Sao Paulo University, Department of Nephrology, Sao Paulo, Brazil; Hess B, Klinik Im Park Hospital, Department of Internal Medicine \& Nephrology, Zurich, Switzerland; Jaeger Ph, University College of London, Centre of Nephrology, London, UK; Kirkali Z, NIDDK, National Institutes of Health, Division of Kidney, Urologic \& Hematologic Diseases, Bethesda, USA; Kok D, Erasmus Medical Center, Department of Urology, Rotterdam, Netherlands; Letavernier E, Tenon Hospital, Department of Nephrology, Paris, France; Lieske J, Mayo Clinic, Department of Laboratory Medicine and Pathology, Rochester, USA; Lingeman J, Indiana University School of Medicine, Department of Urology, Indianapolis, USA; Marangella M, A.S.O Ordine Mauriziano Hospital, Department of Nephrology, Turin, Italy; Mazzaferro S, University La Sapienza, Department of Nephrology, Rome, Italy; Moe O, University of Texas, Southwestern Medical Center, Department of Internal Medicine, Dallas, USA; Milliner D, Mayo Clinic, Department of Nephrology, Rochester, USA; Nouvenne A, University of Parma, Department of Internal Medicine, Parma, Italy; Preminger GM, Duke University Medical Center, Department of Urology, Durham, USA; Prie D, Necker-Enfants Malades Hospital, Department of Physiology, Paris, France; Reis Santos J, Catholic University of Portugal, Department of Urology, Lisbon, Portugal; Rendina D, University of Naples, Department of Internal Medicine, Naples, Italy; Sakhaee K, University of Texas, Southwestern Medical Center, Mineral Metabolism Research, Dallas, USA; Sarica K, Department of Urology, Dr. Lutfi KIRDAR Kartal Research and Training Hospital, Istanbul, Turkey; Siener R, University of Bonn, 
Department of Urology, Bonn, Germany; Soldati L, University of Milan, Department of Dietetic Science, Milan, Italy; Strazzullo P, University of Naples, Department of Internal Medicine, Naples, Italy; Tasca A, San Bortolo Hospital, Department of Urology, Vicenza, Italy; Trinchieri A, Manzoni Hospital, Department of Urology, Lecco, Italy; Vezzoli G, San Raffaele University Hospital, Department of Nephrology, Milan, Italy; Vitale C, A.S.O Ordine Mauriziano Hospital, Department of Nephrology and Dialysis, Torino, Italy; Wu W, Hospital of Guangzhou, Medical College, Department of Urology, Guangzhou, China; Williams JC, Indiana University School of Medicine, Department of Anatomy \& Cell Biology, Indiana, USA; Worcester E., University of Chicago, Medicine, Department of Nephrology, Chicago, USA.

\section{Compliance with ethical standards}

Conflict of interest On behalf of all authors, the corresponding author states that there is no conflict of interest.

Ethical approval No research involving patients or animals have been carried on specifically for this study.

Informed consent For this type of study formal consent is not required.

Open Access This article is distributed under the terms of the Creative Commons Attribution 4.0 International License (http://crea tivecommons.org/licenses/by/4.0/), which permits unrestricted use, distribution, and reproduction in any medium, provided you give appropriate credit to the original author(s) and the source, provide a link to the Creative Commons license, and indicate if changes were made.

\section{References}

1. Pearle MS, Goldfarb DS, Assimos DG et al (2014) Medical management of kidney stones: AUA guideline. J Urol 192(2):316-324

2. Fink HA, Wilt TJ, Eidman KE et al (2013) Medical management to prevent recurrent nephrolithiasis in adults: a systematic review for an American College of Physicians Clinical Guideline. Ann Intern Med 158(7):535-543

3. Skolarikos A, Straub M, Knoll T et al (2015) Metabolic evaluation and recurrence prevention for urinary stone patients: EAU guidelines. Eur Urol 67(4):750-763

4. Alexander RT, Hemmelgarn BR, Wiebe N et al (2012) Kidney stones and kidney function loss: a cohort study. BMJ 345:e5287

5. Shoag J, Halpern J, Goldfarb DS, Eisner BH (2014) Risk of chronic and end stage kidney disease in patients with nephrolithiasis. J Urol 192(5):1440-1445

6. Saucier NA, Sinha MK, Liang KV et al (2010) Risk factors for CKD in persons with kidney stones: a case-control study in Olmsted County, Minnesota. Am J Kidney Dis 55(1):61-68

7. El-Zoghby ZM, Lieske JC, Foley RN et al (2012) Urolithiasis and the risk of ESRD. Clin J Am Soc Nephrol CJASN 7(9):1409-1415

8. Gillen DL, Worcester EM, Coe FL (2005) Decreased renal function among adults with a history of nephrolithiasis: a study of NHANES III. Kidney Int 67(2):685-690

9. Worcester EM, Parks JH, Evan AP, Coe FL (2006) Renal function in patients with nephrolithiasis. J Urol 176(2):600-603 (discussion 603)

10. Prot-Bertoye C, Lebbah S, Daudon M et al (2015) CKD and Its risk factors among patients with cystinuria. Clin J Am Soc Nephrol CJASN 10(5):842-851
11. Lieske JC, Mehta RA, Milliner DS, Rule AD, Bergstralh EJ, Sarr MG (2015) Kidney stones are common after bariatric surgery. Kidney Int 87(4):839-845

12. Bucuras V, Gopalakrishnam G, Wolf JS et al (2012) The Clinical Research Office of the Endourological Society Percutaneous Nephrolithotomy Global Study: nephrolithotomy in 189 patients with solitary kidneys. J Endourol 26(4):336-341

13. Tasca A, Dalle Carbonare L, Nigro F, Giannini S (2009) Bone disease in patients with primary hypercalciuria and calcium nephrolithiasis. Urology 74(1):22-27

14. Melton LJ, Crowson CS, Khosla S, Wilson DM, O'Fallon WM (1998) Fracture risk among patients with urolithiasis: a population-based cohort study. Kidney Int 53(2):459-464

15. Pak CY, Heller HJ, Pearle MS, Odvina CV, Poindexter JR, Peterson RD (2003) Prevention of stone formation and bone loss in absorptive hypercalciuria by combined dietary and pharmacological interventions. J Urol 169(2):465-469

16. Sakhaee K, Maalouf NM, Kumar R, Pasch A, Moe OW (2011) Nephrolithiasis-associated bone disease: pathogenesis and treatment options. Kidney Int 79(4):393-403

17. Bushinsky DA, Willett T, Asplin JR, Culbertson C, Che SPY, Grynpas M (2011) Chlorthalidone improves vertebral bone quality in genetic hypercalciuric stone-forming rats. J Bone Miner Res Off J Am Soc Bone Miner Res 26(8):1904-1912

18. Krieger NS, Asplin JR, Frick KK et al (2015) Effect of potassium citrate on calcium phosphate stones in a model of hypercalciuria. J Am Soc Nephrol JASN 26(12):3001-3008

19. Jehle S, Hulter HN, Krapf R (2013) Effect of potassium citrate on bone density, microarchitecture, and fracture risk in healthy older adults without osteoporosis: a randomized controlled trial. J Clin Endocrinol Metab 98(1):207-217

20. Borghi L, Schianchi T, Meschi T et al (2002) Comparison of two diets for the prevention of recurrent stones in idiopathic hypercalciuria. N Engl J Med 346(2):77-84

21. Miller NL, Williams JC, Evan AP et al (2010) In idiopathic calcium oxalate stone-formers, unattached stones show evidence of having originated as attached stones on Randall's plaque. BJU Int 105(2):242-245

22. Goldfarb DS, Arowojolu O (2013) Metabolic evaluation of firsttime and recurrent stone formers. Urol Clin North Am 40(1):13-20

23. Fabris A, Ferraro PM, Comellato G et al (2015) The relationship between calcium kidney stones, arterial stiffness and bone density: unraveling the stone-bone-vessel liaison. J Nephrol 28(5):549-555

24. Hess B, Hasler-Strub U, Ackermann D, Jaeger P (1997) Metabolic evaluation of patients with recurrent idiopathic calcium nephrolithiasis. Nephrol Dial Transplant Off Publ Eur Dial Transpl Assoc Eur Ren Assoc 12(7):1362-1368

25. Letavernier E, Traxer O, Daudon M et al (2011) Determinants of osteopenia in male renal-stone-disease patients with idiopathic hypercalciuria. Clin J Am Soc Nephrol CJASN 6(5):1149-1154

26. Linnes MP, Krambeck AE, Cornell L et al (2013) Phenotypic characterization of kidney stone formers by endoscopic and histological quantification of intrarenal calcification. Kidney Int 84(4):818-825

27. Wang X, Krambeck AE, Williams JC et al (2014) Distinguishing characteristics of idiopathic calcium oxalate kidney stone formers with low amounts of Randall's plaque. Clin J Am Soc Nephrol CJASN 9(10):1757-1763

28. Dhayat NA, Schaller A, Albano G, et al (2015) The Vacuolar $\mathrm{H}^{+}$-ATPase B1 Subunit Polymorphism p.E161 K Associates with Impaired Urinary Acidification in Recurrent Stone Formers. J Am Soc Nephrol JASN

29. Esposito T, Rendina D, Aloia A et al (2012) The melatonin receptor 1A (MTNR1A) gene is associated with recurrent and 
idiopathic calcium nephrolithiasis. Nephrol Dial Transplant Off Publ Eur Dial Transpl Assoc Eur Ren Assoc 27(1):210-218

30. Ferraro PM, D'Addessi A, Gambaro G (2013) When to suspect a genetic disorder in a patient with renal stones, and why. Nephrol Dial Transplant Off Publ Eur Dial Transpl Assoc Eur Ren Assoc 28(4):811-820

31. Krambeck AE, Handa SE, Evan AP, Lingeman JE (2010) Brushite stone disease as a consequence of lithotripsy? Urol Res 38(4):293-299

32. Krambeck AE, Handa SE, Evan AP, Lingeman JE (2010) Profile of the brushite stone former. J Urol 184(4):1367-1371

33. Evan AP, Lingeman JE, Worcester EM, et al (2014) Contrasting histopathology and crystal deposits in kidneys of idiopathic stone formers who produce hydroxy apatite, brushite, or calcium oxalate stones. Anat Rec Hoboken NJ 2007 297(4):731-48

34. Pak CYC, Poindexter JR, Adams-Huet B, Pearle MS (2003) Predictive value of kidney stone composition in the detection of metabolic abnormalities. Am J Med 115(1):26-32

35. Parks JH, Worcester EM, Coe FL, Evan AP, Lingeman JE (2004) Clinical implications of abundant calcium phosphate in routinely analyzed kidney stones. Kidney Int 66(2):777-785

36. Evan AP, Coe FL, Connors BA, Handa RK, Lingeman JE, Worcester EM (2015) Mechanism by which shock wave lithotripsy can promote formation of human calcium phosphate stones. Am J Physiol Renal Physiol 308(8):F938-F949

37. Zhang J, Fuster DG, Cameron MA et al (2014) Incomplete distal renal tubular acidosis from a heterozygous mutation of the V-ATPase B1 subunit. Am J Physiol Renal Physiol 307(9):F1063F1071

38. Osther PJ, Hansen AB, Röhl HF (1988) Renal acidification defects in patients with their first renal stone episode. Scand J Urol Nephrol Suppl 110:275-278

39. Williams G, Chisholm GD (1975) Stone screening and followup are necessary? Br J Urol 47(7):745-750

40. Pak CYC, Poindexter JR, Peterson RD, Heller HJ (2004) Biochemical and physicochemical presentations of patients with brushite stones. J Urol 171(3):1046-1049

41. Preminger GM, Sakhaee K, Skurla C, Pak CY (1985) Prevention of recurrent calcium stone formation with potassium citrate therapy in patients with distal renal tubular acidosis. J Urol 134(1):20-23

42. Fabris A, Lupo A, Bernich P et al (2010) Long-term treatment with potassium citrate and renal stones in medullary sponge kidney. Clin J Am Soc Nephrol CJASN 5(9):1663-1668

43. Shah J, Whitfield HN (2002) Urolithiasis through the ages. BJU Int 89(8):801-810

44. Coe FL, Raisen L (1973) Allopurinol treatment of uric-acid disorders in calcium-stone formers. Lancet Lond Engl 1(7795):129-131

45. Prien EL, Prien EL (1968) Composition and structure of urinary stone. Am J Med 45(5):654-672

46. Curhan GC, Taylor EN (2008) 24-h uric acid excretion and the risk of kidney stones. Kidney Int 73(4):489-496

47. Coe FL (1978) Hyperuricosuric calcium oxalate nephrolithiasis. Kidney Int 13(5):418-426

48. Coe FL, Kavalach AG (1974) Hypercalciuria and hyperuricosuria in patients with calcium nephrolithiasis. N Engl J Med 291(25):1344-1350

49. Pak CY, Barilla DE, Holt K, Brinkley L, Tolentino R, Zerwekh JE (1978) Effect of oral purine load and allopurinol on the crystallization of calcium salts in urine of patients with hyperuricosuric calcium urolithiasis. Am J Med 65(4):593-599

50. Pak CY, Waters O, Arnold L, Holt K, Cox C, Barilla D (1977) Mechanism for calcium urolithiasis among patients with hyperuricosuria: supersaturation of urine with respect to monosodium urate. J Clin Invest 59(3):426-431
51. Grover PK, Marshall VR, Ryall RL (2003) Dissolved urate salts out calcium oxalate in undiluted human urine in vitro: implications for calcium oxalate stone genesis. Chem Biol 10(3):271-278

52. Grover PK, Ryall RL (2002) The effect of preincubation of seed crystals of uric acid and monosodium urate with undiluted human urine to induce precipitation of calcium oxalate in vitro : implications for urinary stone formation. Mol Med Camb Mass 8(9):525-535

53. Coe FL, Lawton RL, Goldstein RB, Tembe V (1975) Sodium urate accelerates precipitation of calcium oxalate in vitro. Proc Soc Exp Biol Med Soc Exp Biol Med NY N 149(4):926-929

54. Pak CY, Hayashi Y, Arnold LH (1976) Heterogeneous nucleation with urate, calcium phosphate and calcium oxalate. Proc Soc Exp Biol Med Soc Exp Biol Med NY N 153(1):83-87

55. Pak CY, Arnold LH (1975) Heterogeneous nucleation of calcium oxalate by seeds of monosodium urate. Proc Soc Exp Biol Med Soc Exp Biol Med NY N 149(4):930-932

56. Smith MJ (1977) Placebo versus allopurinol for renal calculi

57. Smith MJ (1973) Allopurinol and calcium-stone formers. Lancet Lond Engl 1(7798):315

58. Coe FL (1977) Treated and untreated recurrent calcium nephrolithiasis in patients with idiopathic hypercalciuria, hyperuricosuria, or no metabolic disorder. Ann Intern Med 87(4):404-410

59. Ettinger B, Tang A, Citron JT, Livermore B, Williams T (1986) Randomized trial of allopurinol in the prevention of calcium oxalate calculi. N Engl J Med 315(22):1386-1389

60. Hallson PC, Rose GA (1976) Crystalluria in normal subjects and in stone formers with and without thiazide and cellulose phosphate treatment. Br J Urol 48(7):515-524

61. Daudon M, Jungers P, Lacour B (2004) Clinical value of crystalluria study. Ann Biol Clin (Paris) 62(4):379-393

62. Robertson WG, Peacock M, Nordin BE (1969) Calcium crystalluria in recurrent renal-stone formers. Lancet Lond Engl 2(7610):21-24

63. Robert M, Boularan AM, Delbos O, Guiter J, Descomps B (1998) Study of calcium oxalate crystalluria on renal and vesical urines in stone formers and normal subjects. Urol Int 60(1):41-46

64. Fuselier HA, Moore K, Lindberg J et al (1998) Agglomeration inhibition reflected stone-forming activity during long-term potassium citrate therapy in calcium stone formers. Urology 52(6):988-994

65. Kok DJ, Papapoulos SE, Bijvoet OL (1990) Crystal agglomeration is a major element in calcium oxalate urinary stone formation. Kidney Int 37(1):51-56

66. Hess B, Jordi S, Zipperle L, Ettinger E, Giovanoli R (2000) Citrate determines calcium oxalate crystallization kinetics and crystal morphology-studies in the presence of Tamm-Horsfall protein of a healthy subject and a severely recurrent calcium stone former. Nephrol Dial Transplant Off Publ Eur Dial Transpl Assoc Eur Ren Assoc 15(3):366-374

67. Evan AP, Lingeman JE, Coe FL et al (2003) Randall's plaque of patients with nephrolithiasis begins in basement membranes of thin loops of Henle. J Clin Invest 111(5):607-616

68. Evan AP, Lingeman JE, Coe FL et al (2005) Crystal-associated nephropathy in patients with brushite nephrolithiasis. Kidney Int 67(2):576-591

69. Evan AP, Coe FL, Lingeman JE et al (2006) Renal crystal deposits and histopathology in patients with cystine stones. Kidney Int 69(12):2227-2235

70. Evan AP, Lingeman J, Coe F et al (2007) Renal histopathology of stone-forming patients with distal renal tubular acidosis. Kidney Int 71(8):795-801

71. Evan AE, Lingeman JE, Coe FL et al (2008) Histopathology and surgical anatomy of patients with primary hyperparathyroidism and calcium phosphate stones. Kidney Int 74(2):223-229 
72. Evan AP, Lingeman JE, Coe FL et al (2009) Intra-tubular deposits, urine and stone composition are divergent in patients with ileostomy. Kidney Int 76(10):1081-1088

73. Evan AP, Lingeman JE, Worcester EM et al (2010) Renal histopathology and crystal deposits in patients with small bowel resection and calcium oxalate stone disease. Kidney Int 78(3):310-317

74. Evan AP, Worcester EM, Williams JC, et al (2015) Biopsy proven medullary sponge kidney: clinical findings, histopathology, and role of osteogenesis in stone and plaque formation. Anat Rec Hoboken NJ 2007 298(5):865-77

75. Coe FL, Evan AP, Lingeman JE, Worcester EM (2010) Plaque and deposits in nine human stone diseases. Urol Res 38(4):239-247

76. Daudon M, Bader CA, Jungers P (1993) Urinary calculi: review of classification methods and correlations with etiology. Scanning Microsc 7(3):1081-1104-1106

77. Borofsky MS, Paonessa JE, Evan AP et al (2015) Introduction of a renal papillary grading system for patients with nephrolithiasis. J Endourol Part B Videourol 150626110953002

78. Borofsky MS, Paonessa JE, Evan AP et al (2016) A proposed grading system to standardize the description of renal papillary appearance at the time of endoscopy in patients with nephrolithiasis. J Endourol Endourol Soc 30(1):122-127

79. Strohmaier WL, Hörmann M, Schubert G (2013) Papillary calcifications: a new prognostic factor in idiopathic calcium oxalate urolithiasis. Urolithiasis 41(6):475-479

80. Krambeck AE, Lieske JC, Li X et al (2013) Current computed tomography techniques can detect duct of Bellini plugging but not Randall's plaques. Urology 82(2):301-306

81. Ciudin A, Luque Galvez MP, Salvador Izquierdo R et al (2013) Validation of Randall's plaque theory using unenhanced abdominal computed tomography. Urology 81(2):246-249

82. Zisman AL, Evan AP, Coe FL, Worcester EM (2015) Do kidney stone formers have a kidney disease? Kidney Int 88(6): $1240-1249$

83. Rule AD, Krambeck AE, Lieske JC (2011) Chronic kidney disease in kidney stone formers. Clin J Am Soc Nephrol CJASN 6(8):2069-2075

84. Ferraro PM, D’Addessi A, Alessandro D, Gambaro G, Giovanni $G$ (2015) Randall's plaques, plugs and the clinical workup of the renal stone patient. Urolithiasis 43(Suppl 1):59-61

85. Kasidas GP, Samuell CT, Weir TB (2004) Renal stone analysis: why and how? Ann Clin Biochem 41(Pt 2):91-97

86. Krambeck AE, Khan NF, Jackson ME, Lingeman JE, McAteer JA, Williams JC (2010) Inaccurate reporting of mineral composition by commercial stone analysis laboratories: implications for infection and metabolic stones. J Urol 184(4):1543-1549

87. Primiano A, Persichilli S, Gambaro G et al (2014) FT-IR analysis of urinary stones: a helpful tool for clinician comparison with the chemical spot test. Dis Markers 2014

88. Daudon M, Jungers P, Bazin D (2008) Peculiar morphology of stones in primary hyperoxaluria. N Engl J Med 359(1):100-102

89. Dessombz A, Letavernier E, Haymann J-P, Bazin D, Daudon M (2015) Calcium phosphate stone morphology can reliably predict distal renal tubular acidosis. J Urol 193(5):1564-1569

90. Talati J, Tiselius H-G, Albala DM, Ye Z (eds) (2012) Urolithiasis: basic science and clinical practice. Springer, London

91. Hartman R, Kawashima A, Takahashi N et al (2012) Applications of dual-energy CT in urologic imaging: an update. Radiol Clin North Am 50(2):191-205

92. Williams JC, McAteer JA, Evan AP, Lingeman JE (2010) Micro-computed tomography for analysis of urinary calculi. Urol Res 38(6):477-484

93. Hesse A, Kruse R, Geilenkeuser W-J, Schmidt M (2005) Quality control in urinary stone analysis: results of 44 ring trials (1980-2001). Clin Chem Lab Med 43(3):298-303
94. Mandel N, Mandel I, Fryjoff K, Rejniak T, Mandel G (2003) Conversion of calcium oxalate to calcium phosphate with recurrent stone episodes. J Urol 169(6):2026-2029

95. Daudon M, Bouzidi H, Bazin D (2010) Composition and morphology of phosphate stones and their relation with etiology. Urol Res 38(6):459-467

96. Edvardsson VO, Goldfarb DS, Lieske JC et al (2013) Hereditary causes of kidney stones and chronic kidney disease. Pediatr Nephrol Berl Ger 28(10):1923-1942

97. Strauss AL, Coe FL, Parks JH (1982) Formation of a single calcium stone of renal origin. Clinical and laboratory characteristics of patients. Arch Intern Med 142(3):504-507

98. Mardis HK, Parks JH, Muller G, Ganzel K, Coe FL (2004) Outcome of metabolic evaluation and medical treatment for calcium nephrolithiasis in a private urological practice. J Urol 171(1):85-88

99. Rule AD, Lieske JC, Li X, Melton LJ, Krambeck AE, Bergstralh EJ (2014) The ROKS nomogram for predicting a second symptomatic stone episode. J Am Soc Nephrol JASN 25(12):2878-2886

100. Borghi L, Meschi T, Amato F, Briganti A, Novarini A, Giannini A (1996) Urinary volume, water and recurrences in idiopathic calcium nephrolithiasis: A 5-year randomized prospective study. J Urol 155:839-843

101. Sarica K, Inal Y, Erturhan S, Yağci F (2006) The effect of calcium channel blockers on stone regrowth and recurrence after shock wave lithotripsy. Urol Res 34(3):184-189

102. Kessler T, Hesse A (2000) Cross-over study of the influence of bicarbonate-rich mineral water on urinary composition in comparison with sodium potassium citrate in healthy male subjects. Br J Nutr 84(6):865-871

103. Karagülle O, Smorag U, Candir F et al (2007) Clinical study on the effect of mineral waters containing bicarbonate on the risk of urinary stone formation in patients with multiple episodes of CaOx-urolithiasis. World J Urol 25(3):315-323

104. Siener R, Hesse A (2003) Fluid intake and epidemiology of urolithiasis. Eur J Clin Nutr 57(Suppl 2):S47-S51

105. Ferraro PM, Taylor EN, Gambaro G, Curhan GC (2013) Soda and other beverages and the risk of kidney stones. Clin J Am Soc Nephrol CJASN 8:1389-1395

106. Shuster J, Jenkins A, Logan C et al (1992) Soft drink consumption and urinary stone recurrence: a randomized prevention trial. J Clin Epidemiol 45:911-916

107. Taylor EN, Fung TT, Curhan GC (2009) DASH-style diet associates with reduced risk for kidney stones. J Am Soc Nephrol JASN 20:2253-2259

108. Soldati L, Bertoli S, Terranegra A et al (2014) Relevance of Mediterranean diet and glucose metabolism for nephrolithiasis in obese subjects. J Transl Med 12(1):34

109. Turney BW, Appleby PN, Reynard JM, Noble JG, Key TJ, Allen NE (2014) Diet and risk of kidney stones in the Oxford cohort of the European Prospective Investigation into Cancer and Nutrition (EPIC). Eur J Epidemiol 29(5):363-369

110. Kocvara R, Plasgura P, Petrík A, Louzenský G, Bartonícková K, Dvorácek J (1999) A prospective study of nonmedical prophylaxis after a first kidney stone. BJU Int 84(4):393-398

111. Taylor EN, Stampfer MJ, Curhan GC (2004) Dietary factors and the risk of incident kidney stones in men: new insights after 14 years of follow-up. J Am Soc Nephrol JASN 15(12): 3225-3232

112. Curhan GC, Willett WC, Rimm EB, Stampfer MJ (1993) A prospective study of dietary calcium and other nutrients and the risk of symptomatic kidney stones. N Engl J Med 328(12): 833-838

113. Curhan GC, Willett WC, Speizer FE, Spiegelman D, Stampfer MJ (1997) Comparison of dietary calcium with supplemental 
calcium and other nutrients as factors affecting the risk for kidney stones in women. Ann Intern Med 126(7):497-504

114. Curhan GC, Willett WC, Knight EL, Stampfer MJ (2004) Dietary factors and the risk of incident kidney stones in younger women: Nurses' Health Study II. Arch Intern Med 164(8):885-891

115. Sorensen MD, Kahn AJ, Reiner AP et al (2012) Impact of nutritional factors on incident kidney stone formation: a report from the WHI OS. J Urol 187(5):1645-1649

116. Taylor EN, Curhan GC (2013) Dietary calcium from dairy and nondairy sources, and risk of symptomatic kidney stones. J Urol 190(4):1255-1259

117. Bleich HL, Moore MJ, Lemann J, Adams ND, Gray RW (1979) Urinary calcium excretion in human beings. $\mathrm{N}$ Engl $\mathrm{J}$ Med 301(10):535-541

118. Cappuccio FP, Kalaitzidis R, Duneclift S, Eastwood JB (2000) Unravelling the links between calcium excretion, salt intake, hypertension, kidney stones and bone metabolism. J Nephrol 13(3):169-177

119. Nouvenne A, Meschi T, Prati B et al (2010) Effects of a low-salt diet on idiopathic hypercalciuria in calcium-oxalate stone formers: a 3-mo randomized controlled trial. Am J Clin Nutr 91(3):565-570

120. Taylor EN, Curhan GC (2007) Oxalate intake and the risk for nephrolithiasis. J Am Soc Nephrol JASN 18(7):2198-2204

121. Taylor EN, Curhan GC (2008) Determinants of 24-hour urinary oxalate excretion. Clin $\mathbf{J}$ Am Soc Nephrol CJASN 3(5):1453-1460

122. Meschi T, Maggiore U, Fiaccadori E et al (2004) The effect of fruits and vegetables on urinary stone risk factors. Kidney Int 66:2402-2410

123. La Vecchia C, Decarli A, Pagano R (1998) Vegetable consumption and risk of chronic disease. Epidemiol Camb Mass 9(2):208-210

124. Trinchieri A, Lizzano R, Marchesotti F, Zanetti G (2006) Effect of potential renal acid load of foods on urinary citrate excretion in calcium renal stone formers. Urol Res 34(1):1-7

125. Ferraro PM, Mandel EI, Curhan GC, Gambaro G, Taylor EN (2015) Diet-dependent net acid load, protein intake, and risk of incident kidney stones. J Am Soc Nephrol JASN 26(SA-OR077)

126. Thomas LDK, Elinder C-G, Tiselius H-G, Wolk A, Akesson A (2013) Ascorbic acid supplements and kidney stone incidence among men: a prospective study. JAMA Intern Med 173(5):386-388

127. Ferraro PM, Curhan GC, Gambaro G, Taylor EN (2016) Total, dietary, and supplemental vitamin $\mathrm{c}$ intake and risk of incident kidney stones. Am J Kidney Dis Off J Natl Kidney Found 67(3):400-407

128. Jackson RD, LaCroix AZ, Gass M et al (2006) Calcium plus vitamin $\mathrm{D}$ supplementation and the risk of fractures. N Engl J Med 354(7):669-683

129. Pak CY, Sakhaee K, Fuller CJ (1983) Physiological and physiochemical correction and prevention of calcium stone formation by potassium citrate therapy. Trans Assoc Am Physicians 96:294-305

130. Pak CY, Sakhaee K, Fuller C (1986) Successful management of uric acid nephrolithiasis with potassium citrate. Kidney Int 30(3):422-428
131. Ettinger B, Pak CY, Citron JT, Thomas C, Adams-Huet B, Vangessel A (1997) Potassium-magnesium citrate is an effective prophylaxis against recurrent calcium oxalate nephrolithiasis. J Urol 158(6):2069-2073

132. Sakhaee K, Nicar M, Hill K, Pak CY (1983) Contrasting effects of potassium citrate and sodium citrate therapies on urinary chemistries and crystallization of stone-forming salts. Kidney Int 24(3):348-352

133. Fernández-Rodríguez A, Arrabal-Martín M, García-Ruiz MJ, Arrabal-Polo MA, Pichardo-Pichardo S, Zuluaga-Gómez A (2006) The role of thiazides in the prophylaxis of recurrent calcium lithiasis. Actas Urol Esp 30:305-309

134. Borghi L, Meschi T, Guerra A, Novarini A (1993) Randomized prospective study of a nonthiazide diuretic, indapamide, in preventing calcium stone recurrences

135. Ala-Opas M, Elomaa I, Porkka L, Alfthan O (1987) Unprocessed bran and intermittent thiazide therapy in prevention of recurrent urinary calcium stones. Scand J Urol Nephrol 21(4):311-314

136. Laerum E, Larsen S (1984) Thiazide prophylaxis of urolithiasis. A double-blind study in general practice. Acta Med Scand 215(4):383-389

137. Scholz D, Schwille PO, Sigel A (1982) Double-blind study with thiazide in recurrent calcium lithiasis. J Urol 128(5):903-907

138. Ettinger B, Citron JT, Livermore B, Dolman LI (1988) Chlorthalidone reduces calcium oxalate calculous recurrence but magnesium hydroxide does not. J Urol 139(4):679-684

139. Zillich AJ, Garg J, Basu S, Bakris GL, Carter BL (2006) Thiazide diuretics, potassium, and the development of diabetes: a quantitative review. Hypertension 48(2):219-224

140. ALLHAT Officers and Coordinators for the ALLHAT Collaborative Research Group (2002) The Antihypertensive and LipidLowering Treatment to Prevent Heart Attack Trial. Major outcomes in high-risk hypertensive patients randomized to angiotensin-converting enzyme inhibitor or calcium channel blocker vs diuretic: The Antihypertensive and lipid-lowering treatment to prevent heart attack trial (ALLHAT). JAMA 288(23):2981-2997

141. Breslau NA, Heller HJ, Reza-Albarrán AA, Pak CY (1998) Physiological effects of slow release potassium phosphate for absorptive hypercalciuria: a randomized double-blind trial. J Urol 160(3 Pt 1):664-668

142. Heller HJ, Reza-Albarrán AA, Breslau NA, Pak CY (1998) Sustained reduction in urinary calcium during long-term treatment with slow release neutral potassium phosphate in absorptive hypercalciuria. J Urol 159(5):1451-1455-1456

143. Parks JH, Coe FL, Evan AP, Worcester EM (2009) Urine pH in renal calcium stone formers who do and do not increase stone phosphate content with time. Nephrol Dial Transplant Off Publ Eur Dial Transpl Assoc Eur Ren Assoc 24(1):130-136

144. Buchholz NNP, El Howairis MEF, Durner L et al (2015) Acceptance of mixed scientific and clinical activities in a subspeciality urology meeting. Urolithiasis 43(2):101-105

145. Bos D, Abara E, Parmar MS (2014) Knowledge, attitudes, and practice patterns among healthcare providers in the prevention of recurrent kidney stones in Northern Ontario. Can Urol Assoc J J Assoc Urol Can 8(11-12):E795-E804 